\title{
DEL GONGORINO CONFORTABLE A LA GONGORINA INCÓMODA: LA INSCRIPCIÓN AMERICANA DEL BARROCO A PARTIR DE BOCA DO INFERNO
}

FROM COMFORTABLE GONGORINO TO UNCOMFORTABLE GONGORINA: THE LATIN AMERICAN INSCRIPTION OF THE BAROQUE IN BOCA DO INFERNO Marcela Croce ORCID 0000-0001-6625-1281

Universidad de Buenos Aires Buenos Aires, Argentina

\section{Resumen}

El artículo propone una lectura del barroco brasileño en clave latinoamericana. Con ese propósito, aborda la novela Boca do Inferno de Ana Miranda y la contrasta inicialmente con $O$ sequestro do Barroco na Formação da literatura brasileira: o caso Gregório de Matos de Haroldo de Campos. A partir de la figura de Gregório de Matos, el trabajo postula la necesidad de correlacionar al poeta bahiano con Sor Juana Inés de la Cruz. La hipótesis del texto es que Sor Juana resulta "secuestrada" en el barroco brasileño por la impugnación que realizó al Padre Vieira (otro personaje central de la novela de Miranda) y que sin la inclusión de Sor Juana es imposible definir el barroco en América. El ejercicio apunta a un estudio de caso sobre la necesidad de incluir la literatura brasileńa, de manera más orgánica, a la literatura latinoamericana.

Palabras clave: Barroco brasileńo, Barroco americano, Literatura latinoamericana.

\section{Resumo}

$\mathrm{O}$ artigo propóe uma leitura do barroco brasileiro em chave latino-americana. Com esse propósito, ele lida com a novela Boca do Inferno de Ana Miranda e inicialmente a contrasta com $O$ sequestro do Barroco na Formação da literatura brasileira: o Gregório de Matos de Haroldo de Campos. Com base na figura de Gregório de Matos, o trabalho postula a necessidade de correlacionar o poeta baiano com Sor Juana Inés de la Cruz. A hipótese do texto é que Sor Juana é "sequestrada" no barroco brasileiro por

\section{Abstract}

This article proposes a reading of the Brazilian baroque from a Latin American perspective. With that purpose, the paper analyses Ana Miranda's novel Boca do Inferno and initially contrasts it with O sequestro do Barroco na Formação da literatura brasileira: o caso Gregório de Matos by Haroldo de Campos. Based on the figure of Gregório de Matos, the study highlights the need to correlate the Bahian poet, Matos, with Sor Juana Inés de la Cruz. The paper puts forward the hypothesis that Sor Juana was 
causa do desafio que fez ao padre Vieira (outro personagem central do romance de Miranda) e que sem a inclusão de Sor Juana é impossível definir o barroco na América. O exercício aponta para um estudo de caso sobre a necessidade de incluir a literatura brasileira, de manira mais orgânica, à literatura latinoamericana.

Palavras-chave: Barroco brasileiro, Barroco americano, Literatura latinoamericana. "kidnapped" in the Brazilian baroque because she had defied Father Vieira (another central character in Miranda's novel) and consequently, that it would be impossible to define the baroque in Latin America without including Sor Juana. The paper highlights the need to integrate Brazil literature more organically into Latin American literature.

Keywords: Brazilian Baroque, American Baroque, Latin American Literature.

\section{La sombra (piramidal) de Sor Juana}

Dos inquietudes respecto del Barroco aparecen en Brasil en 1989. Una es la novela Boca do Inferno de Ana Miranda, que convierte en personajes al poeta Gregório de Matos y al obispo jesuita Antônio Vieira. La otra es O sequestro do Barroco na Formação da literatura brasileira: o caso Gregório de Matos de Haroldo de Campos. El recurso narrativo permite en el primer ejercicio fijar menos la atención en las figuras intelectuales que en la ciudad de Bahia que ambos personajes habitan en la década de 1680 en que transcurre el relato. La estrategia de la crítica-que se ampara en tecnicismos y agobia con la proliferación de mayúsculas como énfasis pedagógico- permite a Haroldo entablar una polémica con el enfoque sistematizador de Antonio Candido. Ambos subterfugios exigen una revisión de la historia de la literatura brasileña y reclaman un vínculo con la literatura latinoamericana. El que postula Haroldo se vuelve transparente a partir de citas de Severo Sarduy, José Lezama Lima y Octavio Paz (CAMPOS, 1989, p. 33, 65, 97); el de Ana Miranda opera de soslayo, mediante un desplazamiento que quisiera asociar a la sierpe que obsesionaba a Lezama Lima en tanto figura apta para representar la metáfora gongorina (LEZAMA LIMA, 2014, p. 306-328): sinuosa, inasible, con el movimiento brusco del rayo que ilumina repentinamente y la vocación sibilante que, si en el plano fonológico se pliega a la levedad del soplo, en el orden de la significación convoca el carácter esquivo que arrastra la profecía de la Sibila.

Boca do Inferno y O sequestro do Barroco rehabilitan a Gregório de Matos, figura que ha recibido un tratamiento lateral en las historias de la literatura brasileña, aunque registró suerte diversa en artículos críticos desprovistos de afán sistemático. Así, mientras Sílvio Romero (1888) le reconoce el germen 
de una conciencia nacional y la resistencia a la metrópoli lusa, José Veríssimo (1916) lo reduce a "imitador de Quevedo". Araripe Júnior (1893) descarta la adscripción moralista del poeta y João Adolfo Hansen, en el mismo 1989 en que intervienen Miranda y Haroldo, lo estima un protonacionalista por los mismos motivos que presentaba Romero. En tanto, las biografías registran un éxito mayor: la de Rossini Tavares de Lima (1942) se titula Boca do Inferno y delinea la figura individual a partir de la estructura social; la de Fernando Rocha Peres (2004) a fines de los años 1960 opta por una documentación precisa. Pero la labor de recuperación más representativa es la de Afrânio Peixoto, quien entre 1923 y 1933 publica la obra del bahiano, aunque no se priva de algunas supresiones, en sintonía con las que la $\mathrm{ABL}$ aplicará a la reedición de 1946 del Florilégio da poesía brasileira (1850-1853) de Francisco Adolfo de Varnhagen, quien había seleccionado versos de Matos.

Para Candido, en la Formação da literatura brasileira (1959), los poemas de Gregório son "manifestaçôes literárias" (CANDIDO, 2008) que no alcanzan el estatuto de literatura que atribuye a los textos producidos a partir de la conciencia intelectual y nacional generada por las academias. Sin embargo, en el deslumbrante texto "Dialética da Malandragem" (1970), Matos es recuperado entre "os precursores da comicidade 'malandra' em nossa literatura, valorizado [...] pela sátira desabusada” (CAMPOS, 1989, p. 72). La distancia verificada en la percepción del poeta entre ambas acometidas es la que conduce del historiador de la literatura al ensayista, del estudioso sistemático al lector entusiasta y del trabajo monumental a la iluminación ocasional.

No es mi propósito juzgar el modo de inserción de Gregório en ese ordenamiento. Entiendo, como Haroldo, que el problema fundamental responde a la aplicación de la categoría "barroco" antes que al ejercicio concreto del poeta que, provocativamente -aunque, una vez más, con el antecedente de Campos- me permito llamar "gregoriano", extremando la polisemia. Mi voluntad es mucho menos local que latinoamericana: lo que persigo es la inscripción americana del barroco como fenómeno no solamente transhistórico -como ha demostrado sobradamente Lezama Lima en La expresión americana (1957) y como se confirma a partir de las prácticas neobarrocas y neobarrosas que abruman desde las últimas décadas del siglo XX e insisten con su potencial revulsivo- sino también transnacional. Pensar en términos latinoamericanos exige rechazar el fetichismo del Estado-nación y suspender los nacionalismos ufanistas; primero, para defender una pertenencia comarcana (RAMA, 1979) que excede las fronteras patrias y, luego, para participar de esa utopía intelectual que es la América Latina unida y que en los estudios literarios reclama el empleo de un método comparatista contrastivo (CROCE, 2015).

Lo que Gregório exige es, antes que una reivindicación en la historia de la literatura brasileña, una inscripción en el conjunto americano que 
-voy a sostener- idealmente podría proveerle el modelo de Sor Juana Inés de la Cruz. La presentación del poeta bahiano que escoge la novela de Ana Miranda es excesivamente peninsular y comienza con la resonancia que el soneto "Ilustre y hermosísima María”, de Luis de Góngora, tiene sobre el brasileño. El recurso retórico del carpe diem que en Góngora se resume en el verso "Goza, goza el color, la luz, el oro" antes de que el tiempo los arrebate, en Sor Juana recibe un tratamiento mucho menos complaciente: para ella, los "afeites de carmín y grana" son pobres disimulos de la condición transitoria que aconseja "que es fortuna morirte siendo hermosa/ y no ver el ultraje de ser vieja” (DE LA CRUZ, 2009, p. 390-391). Sor Juana no solamente convoca la inserción de Góngora en América sino que además instaura la convicción de que el Barroco es un invento americano. $\mathrm{O}$ al menos, como se desprende de los enjundiosos ensayos lezamianos, se trata de un modo de tránsito por la experiencia continental.

Sin embargo, en la estela de Lezama, Matos sería antes un quevediano que un gongorino porque, como bien señaló Veríssimo, lo aqueja una recaída moralista que es la misma que el cubano reconoce en el "ojo fruncido" para disparar la ballesta en las reconvenciones que Quevedo cumple bajo la forma de la sátira (LEZAMA LIMA, 2014). La poesía del bahiano se solaza en satirizar las costumbres corruptas antes que en el goce de un significante sustraído a la representación. Postularé entonces que la adscripción gongorina de Matos es un modo de desafiar a Sor Juana -a quien sus contemporáneos le atribuyen escribir al modo de Góngora, como consta en la aclaración introducida en torno al Primero Sueño (DE LA CRUZ, 2009, p. 486)- por el modo en que la monja jerónima devastó un sermón del Padre Vieira en la Crisis de un sermón, difundida como Carta Atenagórica (1690) en que la "mexicana musa" abruma con la sabiduría de Palas Atenea. Alguien podrá objetarme que la novela transcurre en 1683 y que la carta es de 1690; entiendo que la pobreza de esa precisión cronológica no es argumento válido para oponer a la reconstrucción ficcional de Miranda, que participa por igual de las "metaficciones historiográficas" (HUTCHEON, 2014), de la Nueva Novela Histórica (MARTINS, 2015) y de la distinción entre novela e historia que Michel de Certeau (2010) hace descansar sobre los nombres propios, los cuales aparecen connotados en la ficción, en tanto deben cumplir un recorrido de acumulación denotativa en los textos históricos.

La relación entre Gregório y Vieira que traza Boca do Inferno convierte al poeta en un defensor del jesuita. A fin de mantener sin fisuras tal posición, Matos debe desprenderse de cualquier adhesión a Sor Juana, y ningún desprendimiento resulta más eficaz que la obliteración absoluta de su figura. La especulación sobre las derivas de Gregório en caso de nacer en España insiste en este punto: hubiera sido un "gongorino confortable" en 
términos lezamianos; nunca ese gongorino incómodo, desbordante de saber, deslumbrante en su expresión y en su figura dual de religiosa y cortesana que fue Sor Juana. El Barroco americano comienza y culmina en ella. Y en tanto religiosa no se comporta como una católica convencida que emplea la retórica eclesiástica para predicar la ortodoxia, como Vieira, sino al modo de una cristiana primitiva: quien ha ingresado al convento para poder estudiar, y a trueque de evitar el matrimonio (eso declara en la Carta a Sor Filotea), difícilmente ajuste su sensibilidad a la liturgia pero es claro que no logra desgarrarse de la fe.

\section{"El esplendor de la pobreza"}

No obstante, sería excesivamente restrictivo limitar a los personajes la inscripción barroca de la novela. También implicaría otorgarles una responsabilidad que las biografías no podrían soportar. La versión del Barroco que opera en Boca do Inferno se fija especialmente en la antítesis que representa la ciudad de Bahia, primero mediante el sincretismo multicultural que cobija a través de inmigrantes de procedencia exóticas, y luego en la contradicción que se eleva como escándalo urbano y que, extendida, derivará en la fórmula que encuentra Lezama Lima para establecer al Barroco como "el esplendor de la pobreza": "A porta da igreja estaba repleta de miseráveis e loucos. Com tanta riqueza, havia grande pobreza e muita gente morria de fome" (MIRANDA, 2008, p. 11). Tal concentración en lo urbano opera como síntesis de un conjunto de procedimientos que se pueden desglosar con cierto detalle para otorgar a la propia narración el estatuto de novela barroca por la impregnación voluntaria con dicha estética:

a. la experiencia del lenguaje, que no alcanza la condición de "retrolengua" empleada por Enrique Larreta en La gloria de don Ramiro (1908), que en vísperas del Centenario de la Argentina procura restituir los usos lingüísticos de la España de Felipe II. En Boca do Inferno, la asociación con la lengua del Barroco no supera el plano léxico;

b. el sobrevuelo de Sor Juana, tanto por la ausencia del Fénix mexicano en el reconocimiento poético que formula Gregório como por la desestabilización a la que la monja sometió a Vieira;

c. los desvíos que introduce respecto de las formas rectas y la introducción de "perspectivas curiosas" (BALTRUSAITIS, 1977) que encuentran en la anamorfosis sus mejores manifestaciones;

d. el carácter quevediano que afecta a las sátiras de Gregório, enardecidas con el tópico de la ciudad de perdición; 
e. el cruce entre Góngora y Quevedo que intenta conciliar la sierpe gongorina con el moralismo quevediano, para lo cual renuncia a la dimensión más compleja de la obra del cordobés y opta antes por los tópicos barrocos que rezuma que por la disposición del significante que despliega;

f. de modo más episódico: el estilo barroco portugués de ciertas construcciones bahianas como el solar de los Ravasco, modelado sobre los antiguos palacios de Alfama.

Habría que añadir a este repertorio la función que cumple la discursividad barroca reproducida en el texto, concentrada en dos ejercicios: las sátiras de Matos, reconocibles por la rima y la métrica-incluso cuando se las diluye en la linealidad de la prosa-, y los sermones de Vieira. En ambos ejemplos, tales referencias se insertan como reflexiones de los personajes, lo que radicaliza su condición de construcciones verbales, y constituyen el único punto en que asoma un lenguaje barroco (FIGUEIREDO, 2000, p. 33), obtenido por cita antes que por recreación efectiva. Pero lo que en el poeta insiste como gongorismo, en el obispo trasunta el rechazo al culteranismo: en lugar de la metáfora que diseña símbolos complejos, la retórica de Vieira se pronuncia por la alegoría bíblica, "por meio do jogo de ideias e de conceitos num tom persuasivo que segue um raciocínio lógico" (SOUZA SANTANA, 2017, p. 1092). En ese punto Vieira coincide con Maimónides, quien trasuntaba la voluntad de aplicar el razonamiento aristotélico a la exégesis bíblica, y tal vez en esa asociación imprevista radique la preferencia del sacerdote por los "cristianos nuevos", especialmente los judíos (ESTEVES, 2011, p. 17), que en Boca do Inferno serán un auxilio invaluable como el que presta Samuel da Fonseca, aun a riesgo de sacrificar la vida de su hijo Gaspar.

No obstante las inclinaciones por las alegorías sometidas a hermeneusis, la entonación que prevalece en los sermones es la parenética (SOUZA SANTANA, 2017, p. 1092), que apunta a incentivar una conducta moral intachable mediante las verbalidades saturadas de la exhortación, la estimulación y la amonestación. Así se van desgranando en las meditaciones de Vieira extractos del Sermão da Sexagésima, del Sermão pelo Bom Sucesso das armas de Portugal contra as de Holanda, del Sermão do Bom Ladrão y del Sermão da Terceira Dominga da Quaresma (SOUZA SANTANA, 2017, p. 1091, 1097). Desde tal entonación se vislumbra la coincidencia con Gregório, cuyas sátiras mantienen a la reconvención como horizonte. Pero el sermón que continúa ausente, y que es el que vincula directamente a Vieira con Sor Juana, es el Sermão do Mandato, el que la monja jerónima discute al sostener que la mayor fineza del Divino Amor es la Encarnación, y que la misma se manifiesta en el sacramento. Acaso la supresión del debate aspire a evitar el retorno por 
esa vía del Barroco doctrinario, el que impone en el Concilio de Trento los sacramentos como única presencia de la Divinidad, aunque también permita merodear lateralmente por la herejía cátara.

Se sabe que los seguidores más estrictos de los dictados de Trento fueron los jesuitas. Esa orden, verdadero ejército de la Iglesia que operó como falange evangelizadora en América, registra sobresaliente relevancia en Boca do Inferno. La protección que el colegio jesuítico ofrece a los perpetradores del atentado contra el alcalde Francisco Teles de Menezes muestra la dualidad de una organización religiosa que es a la vez oficial y cómplice. La "sobriedad hierática" (MIRANDA, 2008, p. 39) de su iglesia marca la distancia respecto del Barroco no jesuítico, el mismo que llevó a Pedro Henríquez Ureña (1978) a admitir que en América hispánica las grandes obras barrocas eran arquitectónicas y estaban representadas por recintos religiosos como el Sagrario Metropolitano de México, Santa Rosa de Querétaro y Santa Prisca de Taxco. La austeridad de los ignacianos acaso provenga de su organización militar, acaso del retiro en la celda para la práctica de los ejercicios espirituales de afirmación de la fe, acaso de la misión social que cumplen con los indígenas y que los lleva a manejar las lenguas vernáculas y a representar autos sacramentales a fin de impartir el catecismo.

Pero la vocación de desarrollar un Estado autónomo en el interior del engranaje monárquico se volvió demasiado peligrosa para el poder político, como lo confirma la persecución sin cuartel que Braço de Prata aplica sobre Vieira. El obispo desoía las órdenes inquisitoriales contra los judíos y denunciaba -como el dominico Las Casas más de un siglo antes- el trato inclemente que se les daba a los indígenas en estas tierras. Como adoctrinadores de colonias -Brasil, Angola, Goa, Macao (MIRANDA, 2008, p. 197) integran la memoria de la Compañía de Jesús- se asocian al papel que sucesivamente les confirieron Mariano Picón-Salas (1944), Lezama Lima (2014) y Ana Pizarro (1985) a los jesuitas: para el venezolano, se trata de los primeros intelectuales de América; para el cubano son los grandes transportadores de mitos; para la chilena constituyen los exiliados iniciales, a partir del "extrañamiento" que les depararon la corona portuguesa en 1759 y la española en 1767.

\section{La metáfora: el secuestro del referente}

Retomo la mención a la herejía cátara. La hipótesis de Denis de Rougemont (1972) es que los principios de esa reacción anticristiana dieron forma a una manifestación retórica que fue el trobar clus. La oscuridad convenía a un movimiento que descreía de la revelación y cuyo fundamento estimaba que, mientras la circunstancia de que un hombre se convirtiera en un dios era una elevación indudable, el hecho de que un dios encarnara en un hombre resultaba una degradación inconcebible, privada de toda condición 
milagrosa. La oscuridad de enunciación que protegía a los herejes de la vigilancia eclesiástica se expandió a la poesía de la región habitada por los albigenses -el sur de Francia- y definió el estilo de los trovadores provenzales que diseñaron esa forma sofisticada de la metáfora que retorna en el Barroco y encuentra en Góngora al sumo sacerdote de semejante fe laica.

En Boca do Inferno, Gregório en tanto maledicente, practicante de un género propicio al escarnio, está "inspirado em Martim Soares e tantos outros trovadores portugueses" (MIRANDA, 2008, p. 79). En el cierre del texto ("Epílogo. O destino"), que se excede al dar cuenta de la vida ulterior de los personajes indagados durante apenas unos meses de 1683, el gongorismo entonces atenuado del poeta bahiano fortalece su decisión de expresarse "como os trovadores" (MIRANDA, 2008, p. 277). El trobar clus acicatea la aproximación, siempre escatimada por la novela, entre Gregório y Sor Juana; la ficción se abstiene en este punto de arrogarse libertades que puedo reclamar desde la lectura del texto en un marco deliberadamente barroco, corrigiendo con semejante perspectiva voluntariosa lo que podría llamar, remedando a Haroldo en clave latinoamericana, "el secuestro de Sor Juana en el barroco brasileño".

Por una parte, Sor Juana da cauce a una vena satírica como la que despliega Gregório, solo que en lugar de optar por la versión moralizadora del género se pronuncia por la alternativa malandra, allí donde se comporta como "musa del hampa" (FLORES, 2014, p. 9) en el cultivo de las jácaras, en cuyo repentismo se adivina la misma oralidad que lleva al bahiano a mantener sus creaciones "mais para a boca do povo que para os olhos diligentes dos eruditos" (MIRANDA, 2008, p. 186). Por otra parte, el mismo "gongorino confortable" que es Gregório admite que existían dos Góngoras: al lado del popular de los romances y letrillas se alza el grave de los sonetos "rigurosamente vedados al vulgo" (MIRANDA, 2008, p. 94), y que el bahiano es capaz de recitar en español. De hecho, en las mismas sátiras gregorianas resuena el poeta alambicado de las Soledades, el cultista de la Fábula de Polifemo y Galatea y el penumbrosamente filosófico de los sonetos, como confirma el verso "A fortunilha, autora de entremeses" (MIRANDA, 2008, p. 290). La frase constituye la versión portuguesa del verso gongorino "El sueño, autor de representaciones" que encabeza el primer terceto memorable de "Varia imaginación" donde encontró José Bianco el título perfecto para la anamorfosis fantástica tramada en su cuento "Sombras suele vestir" (1942). ${ }^{1}$

Tal dominio lingüístico le permitiría a Matos acceder a los textos de Sor Juana sin mediaciones, como parece desprenderse del poema amatorio que se transcribe en la novela, el cual replica la casuística amorosa compuesta

1 "El sueńo, autor de representaciones,/ en su teatro sobre el viento armado/ sombras suele vestir de bulto bello". 
por Sor Juana en sus sonetos. Mientras en Gregório se organiza una aritmética del gusto, en la mexicana se plasma una geometría de los sentimientos como tentativa de otorgar un orden a lo que difícilmente puede ser racionalizado. Así, los octosílabos de Matos encuentran correspondencia en los endecasílabos de la monja, habilitando el paralelo entre los versos "porque advirta algum doutor/ que sendo a lógica oposto,/ na aritmética do gosto/ pode repartirse-se amor" (MIRANDA, 2008, p. 117) y el cuarteto dilemático "Yo no puedo tenerte ni dejarte, / ni sé por qué, al dejarte o al tenerte,/ se encuentra un no sé qué para quererte/ y muchos sí sé qué para olvidarte" (DE LA CRUZ, 2009, p. 417).

Me detengo por último en la retórica barroca a la que apela Boca do Inferno. Por sobreabundancia, la antítesis, sobre todo aplicada a la multiplicidad de aspectos y costumbres de la ciudad bahiana, más que análisis exigiría sosiego. Algún tópico epocal, como el del mundo al revés, al adosarse de manera machacona al moralismo de las sátiras, reduce su virtualidad a señalamiento episódico: "Roubar uma moeda faz um pirata, roubar uma cidade e seus palácios faz um Alexandre" (MIRANDA, 2008, p. 58). Pero donde aciertan las figuras de discurso a proveer principios constructivos es allí donde incurren en la anamorfosis y la metonimia.

La primera se impone desde la descripción facial de Maria Berco, asistida por la asimetría. En el desafío a tal regla armónica comienza a postularse una forma trastornada que interfiere en el punto de vista de un sujeto para abrirse a una perspectiva multifacetada. Personaje destinado a la percepción ladeada, Maria Berco no solamente la soporta en su cara enrarecida -que por eso mismo atrae a Gregório, acaso fascinado por el modo en que una composición compleja se impone en un rostro para quitarle la insulsez de la naturalidad-sino que la sospecha a través de la mirada que surge de sus ojos desajustados. Así, cuando Bernardo Ravasco le encarga esconder la mano cercenada del alcalde, ella no puede sostener la curiosidad y desenvuelve el paquete con la reliquia siniestra para acceder a la premonición de que allí se perfilaba "o desenho de uma caveira" (MIRANDA, 2008, p. 53).

La calavera fue precisamente la premonición más ominosa en el camino hacia el Barroco, inserta en la obra de Hans Holbein el Joven Los embajadores. En ella, al pie de la perfección simétrica que divide el cuadro entre cada uno de los personajes, y en abierta resistencia a la mostración orgullosa del dominio del mundo que rezuman los instrumentos del quadrivium-geometría, aritmética, música y astronomía, representadas por el compás, el laúd con la cuerda rota y la esfera armilar-, se expande una mancha amarillenta. La perspectiva frontal a la que invita el cuadro exige un desplazamiento hacia el ángulo inferior izquierdo para que esa mancha que perturba la armonía renacentista adquiera sentido. Es el espectador en tránsito que reclama la anamorfosis 
el que descubre que las pinceladas amarillentas definen una calavera, y que detrás de la magnificencia que exhiben los embajadores ese memento mori desbarata cualquier pretensión de orden. En la novela de Miranda no hay embajadores ni armonías fraguadas en el desorden mayúsculo de Bahia: por eso es preciso un personaje lateral, que garantice por su propia asimetría una visión torcida, para detectar la calavera que anuncia la muerte en el marco de excesos prostibularios y falsedades múltiples de la conducta urbana.

Gregório, gran inquisidor de esa ética descastada, no requiere anamorfosis en su presentación sino que se resuelve en la metonimia de una caracterización parcial que le otorga cierto aire de respetabilidad en el conjunto de personajes: "Seus cabelos eram tonsurados porém vestia-se como um leigo, elegante e limpo, com um colete de pelica de âmbar" (MIRANDA, 2008, p. 33). Sus desvíos no revisten impronta física: para eso están Maria con su cara cubista, João da Madre de Deus con un único ojo, Antônio de Souza de Menezes con un solo brazo y el contrahecho Luís Bonicho "o corcunda". En esa insidiosa Corte de los Milagros, mientras Souza de Menezes procura restituir su falta con una ortopedia que es labor de orfebres y tributa a cierto plateresco inquietante, João da Madre de Deus obsequia su condición de tuerto como tentación para el satírico que no establece mayor distinción entre la desgracia física y la decadencia moral porque en ambas encuentra una señal de perdición potenciada por la ciudad. Apenas Bonicho puede escapar a la vulnerabilidad de los objetos sometidos a la sátira cuando acude a la prosapia de jorobados famosos en la que encuentra, si no justificación, al menos consuelo: sin mencionar a los deformes que habitan los cuadros de Diego de Velázquez en el esplendor del barroco hispánico, allí se alistan Sileno, Scaramuccio, Piero della Francesca y Luisa de La Valière (MIRANDA, 2008, p. 201-202).

Pero la deformación más extrema es la que constituye la ciudad misma, que abre y cierra Boca do Inferno en una circularidad que, merced al relato que encierra, parece más propicia a la perspectiva anamórfica que define la elipse (SARDUY, 1987). El círculo es una figura en cuya perfección formal se desalientan las veleidades de la variación para enfatizarse las repeticiones de lo mismo. La novela rechaza esa presunta identidad y opta por acosar al círculo desde el estiramiento elíptico, ya desde el momento en que se aparta de las previsiones biográficas para definir a las figuras protagónicas: el satírico feroz que es Gregório se torna en la novela un hombre enamorado y el obispo ejercitado en los sermones que corresponde al perfil canónico de Vieira se vuelve un sujeto político (ESTEVES, 2011) que defiende a los indios e intima con los judíos.

Bahia es una ciudad letrada (RAMA, 1984) donde la práctica que convoca a los protagonistas es la escritura (ESTEVES, 2011): Gregório 
escribe sus poemas (aunque la narración elige reservarlos a la intimidad del pensamiento y los versos resultan más aptos para una oralidad provocadora y chacotera), Vieira redacta especialmente denuncias encaminadas a la Corona y su hermano Bernardo plasma documentos que son codiciosamente buscados por un poder analfabeto que asocia la escritura secreta con la elocución desafiante. Por cierto, la condición letrada queda reservada a los hombres, ya que aunque Bernardo Ravasco le promete a Maria Berco enseñarle a leer (MIRANDA, 2008, p. 29), su encierro y la posterior prisión de la mujer impiden el cumplimiento del compromiso.

La ciudad adquiere la apostura de un entrelugar en el cual junto a los persas, los turcos y los armenios (MIRANDA, 2008, p. 10) se instalan los transculturados: el obispo nacido en Lisboa, educado en Bahia y viajero por las cortes europeas (ESTEVES, 2011, p. 26) y el poeta nacido en Bahia, educado en Coimbra, deportado a Angola y devuelto a Brasil para instalarse finalmente en Recife. Bahia opera como un oxímoron que cobija tanto el lupanar como la celda monacal y donde la prostituta provee la mejor interlocución y el mayor alivio para el intelectual. Tal condición oximorónica, articulada con la antítesis que campea en las conductas, la metonimia por la cual se accede a la presentación de algunos personajes y la anamorfosis que subraya los rasgos de otros, es uno de los atributos de una novela que, aun impregnándose de rasgos barrocos universales, se muestra menos dispuesta a recomponer el momento para la historia americana que a revisar el período para la literatura brasileña, al precio de renunciar a cualquier comparatismo con la producción latinoamericana contemporánea. Acaso la frugal mención de que a Viera "na Universidade do México me dedicaram umas conclusōes de teología" (MIRANDA, 2008, p. 167) sea el único reconocimiento a la supresión deliberada -al "secuestro" - de Sor Juana en una literatura que no puede estudiarse (menos aún desde la adhesión gongorina a la que aspira Gregório) fuera de la órbita latinoamericana.

\section{Referencias}

ARARIPE JÚNIOR, Tristão de Alencar. Gregório de Mattos. Rio de Janeiro: Garnier, 1904.

BALTRUSAITIS, Jurgis. Anamorphic Art. New York: Harry N. Abrams, 1977.

CAMPOS, Haroldo de. O sequestro do Barroco na Formação da literatura brasileira: o caso Gregório de Matos. Salvador: Fundação Casa de Jorge Amado, 1989.

CANDIDO, Antônio. Dialética da Malandragem. Revista do Instituto de Estudos Brasileiros, n. 8. 1970, p. 67-89. 
CANDIDO, Antonio. Formação da literatura brasileira. Momentos decisivos. Rio de Janeiro: Ouro sobre Azul, 2008.

CERTEAU, Michel de. La escritura de la historia. México: Universidad Iberoamericana, 2010.

CROCE, Marcela. La seducción de lo diverso. Literatura latinoamericana comparada. Buenos Aires: Interzona, 2015.

DE LA CRUZ, Sor Juana Inés. Lírica personal. México: Fondo de Cultura Económica, 2009. Introducción de Antonio Alatorre (IX-XLII).

ESTEVES, Antônio. Ana Miranda y la lectura de la historia literaria brasileña. Gramma, Buenos Aires, v. 22 n. 48, 2011, p. 10-31.

ESTEVES, Antônio. O romance histórico brasileiro contemporáneo (1975-2000). São Paulo: UNESP, 2010.

FIGUEIREDO, Roseana Nunes Bacarat de Souza. Boca do Inferno: reavendo a história. Boletim do Centro de Estudos Portugueses, v. 20, n. 26. São Paulo, 2000, p. 29-36.

FLORES, Enrique. Sor Juana chamana. México: UNAM, 2014.

FONSECA, Ludimilla Carvalho e Gomes, Maria Raimunda. Boca do Inferno: os procedimentos da intertextualidade e da metaficção historiográfica” Litterata. Revista do Centro de Estudos Hélio Simóes, v. 1, n. 1, 2011, p. 11-42.

HANSEN, João Adolfo. A Sátira e o Engenho. Gregório de Matos e a Bahia do século XVII. São Paulo: Companhia das Letras, 1989.

HENRÍQUEZ UREÑA, Pedro. Las corrientes literarias en la América hispánica. México: Fondo de Cultura Económica, 1978.

HUTCHEON, Linda. "Metaficción historiográfica: 'el pasatiempo del tiempo pasado”. Una poética del posmodernismo. Buenos Aires: Prometeo, 2014, p. 195-222.

LEZAMA LIMA, José. Ensayos barrocos. Buenos Aires: Colihue, 2014.

MARTINS, Denis Pereira. Boca do Inferno. Literatura x História: uma interpretação do processo de criação de Ana Miranda" Relegens Thréskeia. Estudos e pesquisas em religiāo, v. 4, n. 2, 2015, p. 168-179.

MIRANDA, Ana. Boca do Inferno. São Paulo: Companhia das Letras, 2008.

PAZ, Octavio. Las trampas de la fe. México: Fondo de Cultura Económica, 1982.

PEIXOTO, Afrânio (ed.). Obras de Gregório de Matos. 6 vols. Rio de Janeiro: Academia Brasileira de Letras, 1923-1933. 
PICÓN-SALAS, Mariano. De la Conquista a la Independencia. Tres siglos de historia cultural latinoamericana. México: Fondo de Cultura Económica, 1944.

PIZARRO, Ana (org.). La literatura latinoamericana como proceso. Buenos Aires: CEAL, 1985.

RAMA, Ángel. Aportación original de una comarca del Tercer Mundo: Latinoamérica. México: UNAM, 1979.

RAMA, Ángel. La ciudad letrada. Montevideo: Arca, 1984.

ROCHA PERES, Fernando. Gregório de Mattos, o Poeta Devorador. Rio de Janeiro: Manati, 2004.

ROMERO, Sílvio. História da literatura brasileira. Rio de Janeiro: Garnier, 1902.

ROUGEMONT, Denis de. L'Amour et l'Occident. Paris: Plon, 1972.

SARAIVA, Daniel Magalhães Porto. A Boca do Inferno. Terceira Margem, Rio de Janeiro, v. 12, n. 18, 2008, p. 111-127.

SARDUY, Severo. Ensayos generales sobre el Barroco. México: Fondo de Cultura Económica, 1987.

TAVARES DE LIMA, Rossini. Gregório de Mattos, o Boca do Inferno. São Paulo: Livraria Élo, 1942.

VERÍSSIMO, José. História da Literatura Brasileira. Rio de Janeiro: Francisco Alves, 1916.

Marcela Croce. Doctora en Letras por la UBA, en cuya Facultad de Filosofía y Letras se desempeña como profesora asociada regular y dirige proyectos de investigación acreditados, de los cuales el último es el que corresponde a la Historia comparada de las literaturas argentina y brasileña (6 volúmenes publicados entre 2016 y 2019). Es autora de una veintena de libros entre los que se destacan CONTORNO. Izquierday proyecto cultural (1996), Osvaldo Soriano, el mercado complaciente (1998), David Viñas: critica de la razón polémica (2005), La seducción de lo diverso (2015) y Latinoamérica, ese esquivo objeto de la teoría (2018), además de compilaciones y ediciones anotadas. E-mail: marcela.croce@gmail.com 